\title{
A QUESTÃO DOS TRABALHADORES TOXICODEPENDENTES SOB 0 PRISMA DA TEORIA DO RECONHECIMENTO DE AXEL HONNETH. DIREITO HUMANO AO TRABALHO E SUA PRETENSÃO DE VALIDADE UNIVERSAL
}

Maria Cecília Máximo TeOdoro

Pós-Doutora em Direito do Trabalho pela Universidade de Castilla-La Mancha com bolsa de pesquisa da CAPES. Doutora em Direito do Trabalho e da Seguridade Social pela USP- Universidade de São Paulo. Mestra em Direito do Trabalho pela Pontifícia Universidade Católica de Minas Gerais. Professora de Direito do Trabalho do Programa da graduação e da Pós-Graduação em Direito, stricto sensu, da PUC/MG e membro reeleita do Colegiado do Programa de Pós-Graduação em Direito da PUC/MG.

Sabrina Colares Nogueira

Doutoranda e Mestra em Direito do Trabalho pela PUC/MG. Especialista em Direito do Trabalho Ítalo-brasileiro pela Universidade Federal de Minas Gerais. Editora da Revista da Faculdade Mineira de Direito. Professora de Direito do Trabalho e Previdenciário. Advogada.

\section{Resumo}

Relacionar a temática referente a Teoria do Reconhecimento de Axel Honnet e o direito humano ao trabalho, como direito humano com pretensão de validade universal, sob a perspectiva da Declaração dos Direitos e Princípios Fundamentais no Trabalho da OIT, com fins de fixar parâmetros de reconhecimento e de (re)inserção social da categoria de trabalhadores toxicodependentes é o principal objetivo do presente artigo. Para tanto, analisaremos o marco teórico em que a persecução da dignidade do homem pelo trabalho é o objetivo do Estado para que a seguir possamos tratar da dignidade do homem como direito cuja pretensão de validade é universal, com base da teoria do reconhecimento de Axel Honneth. Isto posto, podemos analisar a possível dignificação do homem pelo trabalho e no trabalho, em um contexto global a partir dos efeitos do reconhecimento de novos direitos, especialmente no que tange à categoria de trabalhadores que ocupam a parcela social de químico-dependentes, cuja participação no processo social está impedida, gerando uma categoria de trabalhadores socialmente excluídos, o que se pretende ultrapassar. 


\section{Palavras-chave}

Filosofia pós-moderna; Teoria do Reconhecimento; Direito ao trabalho; Direitos humanos.

\section{Abstract}

Relate the theme regarding the Theory of Recognition Axel Honnet, the human right to work as a human right to claim to universal validity, from the perspective of the Declaration of Fundamental Principles and Rights at Work ILO, for purposes of setting parameters and recognition of social (re) integration of chemical class dependent workers is the main goal of this article. We will analyze the theoretical framework in which the pursuit of human dignity at work is the goal of the state to which we treat below the dignity of man as a right whose claim to universal validity is based on the recognition of the theory of Axel Honneth . That said, we analyze the possible dignity of man at work in a global context from the recognition of new rights, especially with regard to the category of workers who occupy the social portion of chemical-dependent, whose participation in the social process is prevented, creating a category of workers socially excluded, which is intended to overcome.

\section{Key words}

Postmodern philosophy; Theory of Recognition; Right to work; Human rights.

\section{Introdução}

Com a fixação do marco teórico na persecução da dignidade do homem no trabalho e pelo trabalho, analisar-se-á a problemática relativa às condutas, na esfera do trabalho, que ferem a dignidade do trabalhador que sofre de dependência química.

Como o trabalhador toxicodependente pode (re)inserir-se no mundo do trabalho pela luta por reconhecimento será o objeto da presente análise.

Pontua-se que não se pretende exaurir o tema relativo a dependência química na esfera do trabalho, tampouco formular tese aceca da teoria do reconhecimento, pois isto não seria possível em apenas um artigo científico.

Pretende-se apenas pontuar a existência desta questão, para que possamos iniciar uma breve reflexão acerca desta nova demanda social, com base na teoria crítica de Axel Honneth, com fins de fixar pilares para o reconhecimento deste novo fato social e dos direitos que envolvem a categoria de trabalhadores toxicodependentes.

\section{Direitos Humanos e sua Pretensão de Validade Universal}

Ao pensar direitos humanos é possível fazer referência a no mínimo dois contextos. Um deles estaria relacionado à teoria jurídica dessa categoria de direitos, que corresponde 
ao conjunto de tratados, convençóes e legislaçóes cujo objeto é a definição destes direitos, bem como a regulação dos mecanismos internacionais e nacionais garantidores dos direitos fundamentais da pessoa humana.

Lado outro, a teoria dos direitos humanos que trata dos fundamentos desses direitos, especialmente no que se refere a análise acerca da validade universal desta categoria de direito, ganha papel de destaque na filosofia social e política contemporâneas, sendo sob este prisma que trataremos de direitos humanos.

Os direitos humanos são a síntese de garantias conquistadas ao longo do desenvolvimento da sociedade, sendo uma síntese progressista, incompleta e mutante. Progressista porque os direitos humanos são resultantes de processos históricos-materiais, pelos quais evoluem constantemente permitindo a realização de barreiras caso haja o retorno a vivências antigas que não foram bem sucedidas, vedando o retrocesso social e humano. É incompleta em conseqüência da sua própria característica de progressão, pois os direitos humanos quando incorporados ao patrimônio do sujeito, impedem que sejam relegados no processo de conformação social, dignificando-o, náo sendo possível a retirada destes direitos. Mutantes porque condicionados ao momento histórico em que surgem, podem sofrer releituras e ter seu conteúdo modificado em períodos históricos futuros.

Neste ponto, Lucas Gontijo ${ }^{1}$, descreve que:

Tanto a definição quando o elenco de tais direitos mudam constantemente [...] A mais remota fonte do que vem a ser direitos humanos se forma no contexto liberal em que surgiram os direitos de primeira geração ou direitos liberais de cunho personalíssimo como os proclamados na Bill of Rights de 1689 ou na Déclaration des Droits de l'Homme et du Citoyen de 1789.

Contudo, o autor pontua que "tais declaraçóes náo esgotam o tema" ${ }^{2}$, visto que nos textos de Karl Marx e de outros autores da época, um embrião do o que hoje se entende por direitos humanos já surgia.

Marx e Engels ao desenvolverem o materialismo histórico demonstram que o Direito funciona como mecanismo de dominação da classe, sendo que em alguns casos os direitos só fazem sentido na vigência de uma ordem capitalista. Nesse sentido que José Adércio Sampaio explica que mesmo as declaraçóes solenes náo libertam o homem, mas sim o condicionam ao sistema capitalista. Assim, ele não é liberado da religião quando

1 GONTIJO, Lucas Alvarenga. Direitos Humanos sob o prisma da Filosofia do Direito: desafios e discursos de justificaçáo dos direitos humanos nas sociedades contemporâneas, p. 3

2 GONTIJO, Lucas Alvarenga. Direitos Humanos sob o prisma da Filosofia do Direito:desafios e discursos de justificação dos direitos humanos nas sociedades contemporâneas. p. 3 . 
obtém a liberdade religiosa, tampouco é liberado da propriedade quando obtém a liberdade de trabalhar ${ }^{3}$.

O aparato estatal estabelece direitos fundamentais com funçóes de dominação ideológica almejando uma estabilidade social, na qual os cidadáos sentem-se respeitados e conquistadores de direitos mínimos. Assim os direitos dão a sensação de justiça e possibilidade de ascensão, já que estão tutelados pelo Estado, e a partir disso, seriam todos iguais. Na terminologia adotada por Marx, tal fenômeno é entendido como alienação. ${ }^{4}$

No entanto, é a Declaração Universal dos Direitos Humanos, adotada pela Organização das Naçóes Unidas em 1948, e, mais recentemente, o Pacto de San José da Costa Rica, de 1969, que primeiro elaboram a ideia de conferir pretensão de validade universal aos direitos humanos.

Lucas Gontijo 5 ainda aponta que:

A gênese da Declaração Universal dos Direitos Humanos ou o Pacto de San José da Costa Rica é efeito de uma narrativa discursiva em prol de direitos que deveriam ser efetivados em decorrência de uma experiência histórica de desrespeitos à humanidade, eles se fizeram como respostas contingenciais, como assentamento de valores aceitos, justificados por uma narrativa racional.

Assim sendo, pensar em direitos humanos é pensar em moral. E este pensar exige uma moral universalizada, tem em vista que a ideia de uma sociedade autônoma náo mais se justifica em um mundo globalizado. Ou seja, com a globalização os povos acabam inseridos em uma mesma linha histórico-cronológica.

Portanto, partindo do pressuposto que as sociedades globalizadas pertencem a um mesmo marco teórico e histórico, é possível conferir, aos sujeitos inseridos neste mesmo marco, direitos humanos universais, ou, pelo menos, direito humanos com pretensâo de validade universal. $\mathrm{O}$ que não acontece quando comparamos o povo brasileiro e uma tribo indígena não-socializada, por exemplo, visto que não pertencem ao mesmo marco histórico.

Deste modo, no contexto da globalização, em que as sociedades prosseguem no marco histórico em sentido regularmente análogo, em que as informaçóes são disseminadas

3 SAMPAIO, José Adércio Leite. Direitos Fundamentais: retórica e historicidade. Belo Horizonte: Del Rey, 2004, p. 44.

4 SILVA, Guilherme Ferreira. Os direitos humanos sob a ótica materialista e procedimentalista. In: Âmbito Jurídico, Rio Grande, XV, n. 105, out 2012. Disponível em: <http://www.ambito-juridico. com.br/site/index.php/?n_link=revista_artigos_leitura\&artigo_id=12290\&revista_caderno=15>. Acesso em set 2014.

5 GONTIJO, Lucas Alvarenga. Direitos Humanos sob o prisma da Filosofia do Direito:desafios e discursos de justificaçáo dos direitos humanos nas sociedades contemporâneas, p. 3 . 
em tempo real, e, principalmente, no contexto de domínio do capitalismo, é sim possível que direitos humanos sejam exigidos universalmente.

Pontua-se ainda que conferir validade universal aos direitos humanos é tarefa que necessita de um remonte acerca da construção de marcos teóricos e de tipos de racionalidade, o que náo será objeto deste estudo.

Por esta razão, trataremos da afirmação da universalidade do direito humano ao trabalho com base na racionalidade da teoria do reconhecimento, da qual passamos a analisar.

\section{Teoria do Reconhecimento em Axel Honneth}

De início, pontua-se que pretende-se apresentar ao leitor uma breve introdução acerca dos conceitos fundamentais da “Teoria do Reconhecimento' de Axel Honneth. Isso significa, dentre outras coisas, que não desenvolveremos nenhuma tese específica acerca desta teoria, tampouco apresentaremos críticas ou análises profundas acerca desta racionalidade.

Ao contrário, pretende-se, tão-somente, reconstruir, de forma simples e clara, os argumentos centrais da teoria do reconhecimento, para embasar o enfrentamento do tema central: a luta por reconhecimento dos trabalhadores toxicodependentes.

Assim sendo, primeiramente, é importante destacar que "é conferido o status filosófico ao conceito de reconhecimento a partir da obra: 'A Dialética do Senhor e do Escravo' na Fenomenologia do Espírito de $\mathrm{Hegel}^{6}$. Contudo, é Axel Honneth, expoente da teoria crítica da Escola de Frankfurt, que difunde a "Teoria do Reconhecimento", em dois momentos distintos.

Em um primeiro momento, Honneth procurou demonstrar as insuficiências da versão da teoria crítica desenvolvida por Jürgen Habermas, que, em suma, tenta reestabelecer o patamar civilizatório da razão com base do paradigma comunicacional, sem considerar a intersubjetividade social na qual as instituições estáo inseridas, razão pela qual sua teoria seria falha.

Em um segundo momento, "Honneth desenvolve sua teoria da razão tendo como ponto de partida o conceito hegeliano de luta por reconhecimento", no intuito de demonstrar principalmente que uma teoria crítica da sociedade deveria estar preocupada em interpretar a sociedade a partir de uma categoria, isto é, do reconhecimento.

6 ASSY, Bethânia; FERES JÚNIOR, João. Reconhecimento.

7 RICOEUR, Paul. Percurso do reconhecimento. p. 34.

SOBOTTKA, Emil A.. Liberdade, reconhecimento e emancipaçáo - raízes da teoria da justiça de Axel, p.34. 
Destaca-se que a palavra reconhecimento correspondente a tradução da palavra $A n$ erkennung, em alemão, e não possui o mesmo sentido da língua portuguesa.

Bethânia Assy e João Feres ${ }^{8}$ definem que "o conceito filosófico de reconhecimento não significa simplesmente a identificação cognitiva de uma pessoa, mas sim, tendo esse ato como premissa, a atribuição de um valor positivo a essa pessoa, algo próximo do que entendemos por respeito".

Ainda na tentativa de compreender o significado da palavra reconhecimento, Charles Taylor ${ }^{9}$ pontua que para compreender o conceito de reconhecimento é preciso compreender os conflitos e demandas da humanidade, especialmente nos casos de movimentos nacionalistas, de conflitos culturais e religiosos, nas causas feministas e nas lutas das minorias políticas. Sua tese é de que "nossa identidade é em parte formada pelo reconhecimento ou pela falta dele" ${ }^{10}$, isto porque nos definimos pelo outro.

Já Paul Ricoeur ${ }^{11}$ também pontua que 'o reconhecimento' vai além da simples identificação e até a gratidão, ou seja, não é apenas uma cortesia que nós devemos às pessoas.

Mas é em Axel Honneth, em sua obra "Luta por Reconhecimento" ${ }^{12}$, que a sistematização de uma teoria do reconhecimento ocorre.

Honneth fundamenta a teoria do reconhecimento a partir do jovem Hegel, sustentando que além dos fenômenos políticos a luta por reconhecimento ultrapassa a questáo da autoconservação, como sustenta a filosofia maquiaveliana-hobbesiana, por exemplo, concentrando-se na questão não utilitarista, mas sim moral, conforme analisa Araújo $\mathrm{Neto}^{13}$.

Este é o grande avanço teórico trazido por Honneth. Ao supor que o fundamento da teoria do reconhecimento é a experiência do desrespeito, ou seja, o não reconhecimento, Honneth fixa que a luta por reconhecimento "é a fonte emotiva e cognitiva de resistência social e de levantes coletivos". ${ }^{14}$

Portanto, luta social ou luta por reconhecimento seria "o processo prático no qual experiências individuais de desrespeito são interpretadas como experiências cruciais típicas de um grupo inteiro, de forma que elas podem influir, como motivos diretores da ação, na exigência coletiva por relaçôes ampliadas de reconhecimento". ${ }^{15}$

8 ASSY, Bethânia; FERES JÚNIOR, João. Reconhecimento. p. 705.

9 TAYLOR, Charles. The politics of recognition.

10 TAYLOR, Charles. The politics of recognition. p. 25-73.

11 RICOEUR, Paul. Percurso do reconhecimento. p. 23.

12 HONNETH, Axel. Luta por reconhecimento: a gramática moral dos conflitos sociais.

13 ARAÚJO NETO, José Aldo Camurça de. A categoria "reconhecimento" na teoria de Axel Honneth, p. 78.

14 HONNETH, Axel. Luta por reconhecimento: a gramática moral dos conflitos sociais. p.257.

15 HONNETH, Axel. Luta por reconhecimento: a gramática moral dos conflitos sociais. p. 58. 
Assim sendo, as lutas por reconhecimento ganham outra dimensão, passando a ser o alicerce para o progresso social, o que reflete no Direito, que é produto da dialética, da tensão.

É preciso ainda destacar que a teoria do reconhecimento honnethiana classifica as formas de reconhecimento em dimensóes, sendo elas: o amor, o direito e a solidariedade.

O reconhecimento a partir do amor ocorre quando o sujeito tem sua subjetividade psíquica desrespeitada, e, por confiar em si mesmo, ou seja, ao identifica-se como sujeito e acreditar em suas possibilidades, consegue enfrentar este desrespeito, o que lhe permite a auto-realização.

Já na esfera do direito, a luta por reconhecimento ocorre após a individualização do sujeito, que passa a ser reconhecido como sujeito de direito, e havendo privação destes direitos, inicia-se a luta por reconhecimento.

Pontua-se também que ao haver a individualização do sujeito de direito, autônomo e moralmente imputável, a obrigação de respeito ao direito surge, o que reafirma o reconhecimento.

$\mathrm{Na}$ esfera da solidariedade, a teoria do reconhecimento define que a luta por reconhecimento está vinculada de tal forma a uma vida em comunidade. Neste contexto é que Honneth cita a esfera do trabalho como "ambiente no qual os indivíduos poderiam mostrar-se valiosos para a coletividade" ${ }^{16}$

Neste campo, a luta por reconhecimento inicia-se com a "degradação moral" e a "injúria" ${ }^{17}$. Ou seja, aqui a experiência do desrespeito é encontrada na degradação da autoestima coletiva, havendo a privação da possibilidade de desenvolver-se em comunidade.

Honneth ${ }^{18}$ classifica ainda estas formas de desrespeito como patologias, servindo a teoria do reconhecimento como indicador dos sintomas que os atores sociais atingidos por esta patologia deixam transparecer.

Finalmente, é preciso pontuar que, em meio aos que sofreram os efeitos desta 'patologia,' ou seja, os 'não reconhecidos', a figura do 'líder' do 'eu forte' é necessária para que o motim ocorra, e, portanto, estará sempre presente na luta por reconhecimento.

Isto porque, em determinado momento, frente ao 'não reconhecimento', um integrante da parcela social que sofre esta 'patologia' inicia o questionamento que é o mote da luta por reconhecimento. Ou seja, a frustração é que deflagra a batalha por reconhecimento.

16 ARAÚJO NETO, José Aldo Camurça de. A categoria "reconhecimento" na teoria de Axel Honneth, p.142.

17 HONNETH, Axel. Luta por reconhecimento: a gramática moral dos conflitos sociais, p. 67

18 HONNETH, Axel. Luta por reconhecimento: a gramática moral dos conflitos sociais, p. 70-75. 
Isto posto, é sob o paradigma das dimensóes de reconhecimento elaboradas por Honneth que analisaremos a luta por reconhecimento dos trabalhadores toxicodependentes, que, ao terem o direito humano ao trabalho atacado pela patologia do 'não reconhecimento', lutam por este reconhecimento.

\section{Direito ao Trabalho e Direitos Efetivos no Trabalho como Direito Humano Universal}

Antes de enfrentar a questão do desrespeito ao direito humano universal ao trabalho, bem como antes de fixar parâmetros pelo reconhecimento deste direito face a categoria de trabalhadores toxicodependentes, é preciso fixar o direito ao trabalho como direito humano universal.

Para falar de direito humano ao trabalho é preciso ultrapassar a figura do trabalho como desrealizador, tal como reduzido pela modernidade capitalista, sob pena de torna inócua a discussão acerca da dignificação pelo trabalho.

Certo é que diversos sociólogos e filósofos críticos de qualquer elogio ao trabalho devem ser citados, como Benjamin ${ }^{19}$, Habermas e Dejours ${ }^{20}$, que tratam o trabalho como forma de alienação capitalista, objetivante e desrealizador, apresentando em suas teorias horizontes aparentemente inexcedível.

Contudo, a (re)construção do paradigma do trabalho, como direito humano, parte do pressuposto de que o trabalho náo significa, simplesmente a objetação e a alienação do homem, mas, sim, o trabalho decente, vivo e não alienado, importando na realização do sujeito, bem como possibilitando sua (re)inserção social.

Fábio Konder Comparato ${ }^{21}$ afirma ser o direito ao trabalho "a pedra angular da construção de uma verdadeira sociedade democrática”.

Neste contexto, a interpretação de Marx feita por Enrique Dussel ${ }^{22}$ é chave para a compreensão da não identidade entre trabalho vivo (trabalho como não capital) e trabalho objetivado (trabalho como capital), senão vejamos.

El trabajo, puesto como no-capital en cuanto tal, es: 1) Trabajo noobjetivado, concebido negativamente... el trabajo vivo, existente como abstracción de estos aspectos de su realidad real; este despojamento total, esta desnudez de toda objetividad, esta existencia puramente subjetiva del trabajo. El trabajo como pobreza absoluta: la pobreza no como acrencia,

19 Benjamin A Modernidade e os Modernos.

20 DEJOURS, Jacques Christophe. A loucura do trabalho: estudo de psicopatologia do trabalho.

21 COMPARATO, Fábio Konder. A afirmação histórica dos direitos humanos. p. 345.

22 DUSSEL, Hacia um Marx desconocido: un comentario de los manuscritos del 61-63. 
sino como exclusión plena de la riqueza objetiva... um a objetividad que coincide con su inmediata corporalidad... 2) Trabajo noobjetivado: novalor, concebido positivamente... como actividad... como la fuente viva del valor... No es en absoluto una contradicción afirmar, pues, que el trabajo por un lado es la pobreza absoluta como objeto, y por otro es la posibilidad universal de la riqueza como sujeto y como actividad; o más bien, que ambos términos de esta contradicción se condicionan mutuamente y derivan de la esencia del trabajo, ya que éste, como ente absolutamente contradictorio con respecto al capital, es un presupuesto del capital y, por otra parte, presupone a su vez al capital. ${ }^{23}$

Ou seja, há sim um trabalho já subsumido pelo capital, alienado, ao qual não se deve conferir o status de direito humano. Contudo, há também uma subjetividade corporal do trabalhador que, enquanto trabalho vivo, sua existência de nenhuma forma é uma determinação do capital.

Reside aí o trabalho como direito humano, e é sob este paradigma que trabalharemos o trabalho como direito humano universal, e uma vez já definidos os contornos do que são direitos humanos universais, é preciso destacar que o trabalho e/ou o direito ao trabalho é protagonista na seara dos direitos humanos.

A Declaração Universal de Direitos Humanos, datada de 1948, no primeiro parágrafo do artigo 23, proclama o direito ao trabalho como direito fundamental, ao definir que: "toda pessoa tem direito ao trabalho, à livre escolha de seu trabalho, a condiçóes equitativas e satisfatórias de trabalho e à proteção contra o desemprego".

O Pacto dos Direitos Humanos, Econômicos, Sociais e Culturais de 1966, ratificada pelo Brasil em 1992, em seu artigo 6º , reconhece o direito ao trabalho como direito humano, ao prever que à toda pessoa deve ser assegurado o acesso ao trabalho livre assim como a proteção à sua manutenção.

Também a Organização Internacional do Trabalho - OIT - reafirma o trabalho como direito humano dignificador e não alienado.

Ao dispor, em sua Convenção 122 da Organização Internacional do Trabalho - OIT, ratificada pelo Brasil com o Decreto Legislativo 61, de 30.11 .1966 e incorporada ao direito interno pelo Decreto 66.499, de 27.04.1970, que o trabalho é direito de todas as pessoas disponíveis e em busca de trabalho; pontuando que o trabalho seja o mais produtivo possível; que seja possível a livre escolha de emprego, devendo ser assegurado a todo trabalhador possibilidades de adquirir e de utilizar, neste emprego, suas qualificaçóes, assim como seus dons, vendando qualquer tipo de discriminação, a OIT reafirma o trabalho como direito humano universal.

23 Marx, apud, DUSSEL, La producción teórica de Marx: un comentario a los Grudrisse, México, p. 138-139 e 336. 
Há que se falar também do direito humano ao trabalho digno, o que implica ao respeito aos direitos trabalhistas e a dignidade do trabalhador na relação de emprego.

Quando Honneth trata da relação entre sujeitos contrapostos, ele as denomina uma interação de "desigualdade". Assim, quando um dos sujeitos é lesado sua reação é fazer com que seu opositor tome consciência dele, levando-o a conhecer o saber intersubjetivo que possui de si mesmo. Desta forma, ele revela ao seu contraposto que ele não possui exatamente este saber de si mesmo, já que sua ação não teve consentimento intersubjetivo. ${ }^{24}$

Essa relação entre desiguais, no contexto da relaçáo de emprego mostra que a reação do lesado, quase sempre o trabalhador, não é motivada tão somente pela ofensa ou pela tomada da posse em si, mas pelo fato de o empregador que o lesou não ter percebido, ou ter ignorado, a sua condição.

Desta forma, diante desta construção teórica, é preciso compreender a responsabilidade social da empresa ou do empregador no contexto da relaçáo de emprego, mediante a qual ela deve reconhecer seus empregados, respeitando-o enquanto trabalhador dotado de dignidade e direitos e acolhendo-o nos momentos de dificuldade.

Em sendo o conflito algo intrínseco ao contexto da relação capital - trabalho, parece crível, adequada e necessária a afirmação da incondicionalidade moral da vontade do trabalhador, objetivando tornar sua pessoa merecedora de reconhecimento por parte de seu empregador.

Quando um indivíduo se vê lesado ou atingido de certa forma por outro indivíduo, e comete em represália um ato destrutivo contra o mesmo, não está reagindo por medo da ameaça atual e futura que representa este sujeito, mas sim porque suas expectativas de reconhecimento por parte do outro não foram atendidas. Aqui se percebe o fundamental da argumentação hegeliana, de acordo com Honneth, que é o fato de que nas relações de interação entre os sujeitos está subentendida a expectativa de reconhecimento pelos outros sujeitos. O sujeito lesado reage por se ver ignorado em sua condição pelo outro sujeito, por não se ver de qualquer forma conhecido pelo outro, e náo porque quer aumentar seu poder relativo ou satisfazer suas necessidades sensíveis. ${ }^{25}$

Assim, a empresa ou o empregador, na prática cotidiana de restriçóes e desrespeito aos direitos humanos mínimos dos trabalhadores, acaba impedindo o sujeito de ver seu direito de igualação perante o próximo e perante o seu contraposto efetivado, levando-o a

24 RAVAGNANI, Hebert Barucci. Luta por reconhecimento: a filosofia social do jovem Hegel segundo Honneth. Kínesis, vol. I, n. 01, Março, 2009, p. 48-49.

25 RAVAGNANI, Hebert Barucci. Luta por reconhecimento: a filosofia social do jovem Hegel segundo Honneth. Kínesis, vol. I, n. 01, Março, 2009, p. 47. 
um sentimento de exclusão social, como se existisse um direito para os ricos e outro para os pobres.

Logo, uma vez violado o direito humano ao trabalho, presentes estarão as 'patologias' definidas por Honneth, em suas dimensóes da teoria do reconhecimento, mote da presente discussão.

Ou seja, quando o trabalhador dependente químico sofre o ataque das patologias descritas pela teoria do reconhecimento, o 'eu forte' terá o motivo necessário à luta por reconhecimento, como se enfrentará logo após uma breve digressão acerca da dependência química no mundo do trabalho.

\section{0 Trabalhador Toxicodependente e as Formas de Não Reconhecimento}

Uma prévia e breve digressão acerca dos conceitos de dependência química é necessária para a discussão acerca das formas de 'não reconhecimento' na esfera da categoria dos trabalhadores toxicodependentes, especialmente no que tange ao desrespeito ao direito humano ao trabalho, para que assim seja possível enfrentar o problema central da presente análise.

De início, é preciso definir o termo 'dependente químico' para fins da presente discussão.

A dependência química, no contexto desta pesquisa, refere-se à dependência de drogas ilícitas, cujos sintomas cognitivos são: comportamentais e fisiológicos que indicam que o indivíduo necessita do consumo de droga para sobrevivência, ${ }^{26}$ nos termos da definição trazida pela Organização Mundial da Saúde.

Já o termo 'droga', será a aqui tratado como sendo substâncias ilícitas, visto que não controladas pelo Estado, capazes de alterar as funçóes cerebrais do indivíduo, seja para lhe proporcionar um aumento forçado da capacidade de concentração, colocando-lhe em um estado de alerta exagerado, sejam aquelas alucinógenas, capazes de alterar todo o estado de consciência do dependente, conforme define a Organização Mundial da Saúde ${ }^{27}$.

Cabe ressaltar que a questão da dependência química é fonte de consideráveis controvérsias. A noção de dependência como enfermidade já vem sendo questionada há algumas décadas e no século XXI tornou-se alvo de acirradas discussóes ao ser posta como enfermidade no contexto da relação de trabalho.

Contudo, certo é que, desde os anos 2000, a Organização Mundial da Saúde - OMS 28 considera a dependência química como uma doença e recomenda que as autoridades

26 OMS. Informaçóes sobre drogas. p.23.

27 OMS. Informaçóes sobre drogas. p. 31.

28 OMS. Relatório Mundial de Saúde. 
encarem o assunto como questão de saúde pública. Mas, apenas nos últimos trinta anos esta dependência química passou a ser realmente tratada na esfera do Direito como uma doença, com sintomas e sinais bem definidos.

Segundo dados de 2010 da $\mathrm{OMS}^{29}$ aproximadamente 2 bilhóes de pessoas consomem drogas. Seu uso indevido é um dos principais fatores que contribuem para a diminuição da saúde mundial, sendo responsável por 3,2\% de todas as mortes e por 4\% de todos os anos perdidos de vida útil. Quando esses índices são analisados em relação à América Latina, o uso de drogas assume uma importância ainda maior. Cerca de 16\% dos anos e vida útil perdidos neste continente estão relacionados ao uso indevido de drogas, índice quatro vezes maior do que a média mundial.

No Brasil, as regiões mais atacadas pelo consumo de drogas, e, portanto, pela dependência química, são as regióes Sudeste e Nordeste ${ }^{30}$, no percentual de 24,5\% 27,6\% por cento da população, respectivamente.

Certo é que a questão da dependência química permeia, hodiernamente, todas as esferas sociais. Enquanto na esfera da educação a preocupação se foca no contexto da prevenção, na esfera das políticas de saúde, o foco está na recuperação dos que foram acometidos por esta enfermidade, como bem classifica a Organização Mundial de Sáude ${ }^{31}$.

$\mathrm{Na}$ esfera do trabalho não é diferente, a dependência química tanto impede o acesso ao trabalho, quanto impede sua manutenção. Isto porque o trabalhador químico-dependente é gravemente discriminado e impedido de ter acesso aos postos de trabalho, lhes restando os trabalhos precários, alienados. Já quando o acesso ao trabalho lhes é concedido, a sua manutenção é dificílima, tendo em vista que a dependência química ainda é vista pela sociedade como transgressão.

Segundo o Relatório Brasileiro sobre drogas, na região Sudeste, "o afastamento do trabalho em decorrência da dependência química chega a ' $0,5 \%$ ou mais' da população de trabalhadores ativos ${ }^{32}$ ", índice alarmante considerando que a população de trabalhadores ativos na região Sudeste supera 41 milhóes de pessoas ${ }^{33}$.

Nas empresas, o abuso de substâncias tem sido associado a acidentes, absentismo e perda de produtividade. Por esta razão, o alcoolismo é a origem de custos para os diferentes setores da atividade econômica e para a comunidade, da ordem de milhóes de dólares.

29 LARANJEIRA, Ronaldo; PINSKY, ILana; ZALESKI, Marcos; CAETANO, Raul. I levantamento nacional sobre os padrōes de consumo de álcool na população brasileira. p. 23

30 Brasil. Relatório brasileiro sobre drogas, p.19

31 Brasil. http://www.datasus.gov.br/cid10/V2008/cid10.f79htm

32 Brasil. Relatório brasileiro sobre drogas, p.23

33 http://www.ibge.gov.br/home/estatistica/indicadores/trabalhoerendimento/pme/pmemet2.shtm 
A OIT em estudo intitulado 'Problemas ligados a álcool e drogas no local de trabalho: uma evolução para prevenção' ${ }^{34}$ analisou que cerca de 40 por cento dos acidentes de trabalho envolvem trabalhadores que consomem drogas; que os trabalhadores químico-dependentes tendem a ausentar-se do trabalho sem autorizaçáo e a faltarem ao trabalho mais frequentemente do que os outros trabalhadores.

Ainda segundo este estudo, um importante fabricante de automóveis, cujo o nome não foi revelado, verificou que os trabalhadores que consomem drogas apresentavam padrôes regulares de absentismo às segundas-feiras.

A propósito, a $\mathrm{OIT}^{35}$, neste mesmo estudo, descreve que:

Os vários problemas relacionados como o álcool e outras drogas no local de trabalho, que se estima custarem milhóes de dólares todos os anos, fazem parte de um conjunto de assuntos relacionados coma a saúde dos trabalhadores, o bem-estar e a segurança, a produtividade nos locais de trabalho e a responsabilidade civil.

Pontua-se que Dejours ${ }^{36}$ já destacou que as contradiçôes da relação entre capital e trabalho são os motivos que conduzem ao adoecer do trabalhador e ao sofrimento físico, psíquico e emocional, razóes pelas podem desencadear a dependência química do trabalhador, por exemplo.

Náo obstante, não analisaremos no momento a causa da dependência química ora tratada, ou seja, se o trabalho poderia ou seria a causa da dependência química, questão que necessita de outro estudo mais específico.

Certo é que, sem o tratamento adequado, a dependência química no meio do trabalho leva a destruição gradativa do trabalhador, atingindo sua vida pessoal, familiar, profissional e social.

Em função disto, muitas são as instituiçôes junto à sociedade civil que têm se proposto a desenvolver um trabalho de assistência e tratamento dos químico-dependentes: grupos anônimos, clínicas ou casas de recuperação, hospitais, etc..

O próprio órgão de previdência social brasileiro já concede ao trabalhador auxílio doença para tratamento da dependência de drogas ${ }^{37}$.

No entanto, as limitaçóes ao reconhecimento da categoria dos trabalhadores dependentes químicos é algo a ser perseguido, como passemos ao debate acerca das

34 OIT. Problemas ligados a álcool e drogas no local de trabalho: uma evolução para prevenção. 2008. p.38

35 OIT. Problemas ligados a álcool e drogas no local de trabalho: uma evolução para prevenção. 2008. p.8.

36 DEJOURS, Jacques Christophe. A loucura do trabalho: estudo de psicopatologia do trabalho

37 Notícia obtida no sitio eletrônico do Instituto Nacional do Seguro Social, disponível em: SS.http:// wwwl.previdencia.gov.br/agprev/agprev_mostraNoticia.asp?Id=49396\&ATVD=1\&xBotao=2.Acessado em 20/11/2013. 
condutas praticadas contra o direito ao trabalho face a categoria de trabalhadores dependentes químicos.

\section{Do Não Reconhecimento do Direito ao Trabalho aos Trabalhadores Toxico- dependentes}

Como já visto, o direito ao trabalho é direito humano com pretensão de validade universal e, quando atacado, poderá deflagrar a luta por reconhecimento.

Neste contexto, em razão das diversas dificuldades de executar o contrato de trabalho; tendo em vista os diversos sintomas e reflexos da dependência química, os trabalhadores químico-dependentes são expostos a um processo de negaçáo de direitos, e, portanto, de exclusão social, 'não reconhecimento', ao perderem seu trabalho em razáo da dependência química, ou, em razão da dificuldade de inserção no mercado de trabalho, seja durante a dependência química, seja após o retorno do tratamento.

No que tange ao náo reconhecimento do direito universal ao trabalho, durante o contrato de trabalho, citemos o indivíduo, dependente químico, que, conforme dados da OIT $^{38}$, tende a chegar ao trabalho mais tarde e a sair mais cedo do trabalho em comparação aos outros trabalhadores não dependentes químicos.

Quando isso ocorre, haverá maior sobrecarga de trabalho para os trabalhadores não químico-dependentes, para compensar a menor produtividade dos trabalhadores químico-dependentes que faltaram ao trabalho, o que, em regra, por motivos individuais ou por ausência do coletivismo, gera queixas e conflitos, seja por parte do trabalhadores não químico-dependentes, seja pelo empregador.

A consequência disso é, além da maior pressão sob o dependente químico, o que, por certo o levará ao consumo maior de drogas, a possibilidade de dispensa deste trabalhador.

Ou seja, neste caso, o trabalho é subsumido pelas necessidades do capital, assim como a conduta humana, pois o trabalhador que não sofre de dependência química, ao ser pressionado por mais trabalho, volta-se contra seu par.

Neste contexto, Dejours ${ }^{39}$ brilhantemente expóe:

Hoje o grande palco do sofrimento nas sociedades neoliberais é certamente o do trabalho. Nas empresas, cada vez mais adotam-se métodos de gestấo que questionam as conquistas sociais, lançam mão da ameaça e apóiam-se na precarização do emprego para obter dos trabalhadores produtividade, disponibilidade e abnegação sempre maiores. Com base nos

38 OIT. Problemas ligados a álcool e drogas no local de trabalho: uma evolução para prevençáo, p.36

39 DEJOURS, Christophe. A banalização da injustiça social, p. 35-80. 
conceitos de banalidade do mal e de distorção comunicacional, o autor descreve um processo que funciona como uma armadilha: a aceitação do sofrimento e das pressóes no trabalho mediante a adoção de estratégias coletivas de defesa. A adoção dessas estratégias permite-lhes continuar a participar do sistema, mas, paradoxalmente, acabam por precarizar não somente o emprego, mas toda a condiçáo social e existencial - desdramatizando o mal, atenuando as reações de indignação e a mobilização coletiva para a ação em prol da solidariedade e da justiça.

Assim sendo, o trabalhador dependente químico, em razão do não reconhecimento do seu indivíduo como sujeito enfermo, como define Honnet ${ }^{40}$ em sua primeira classificação, sofre violação ao seu direito ao trabalho, direito humano universal, mote da luta por reconhecimento.

Contudo, isso ocorre no contexto em que o trabalho é subsumido pela capital, pois, caso contrário, redes de solidariedade propiciariam o reconhecimento do problema social e não o negariam.

Outro contexto de desrespeito ao direito ao trabalho ocorre quando o trabalhador, dependente químico, ausenta-se do trabalho em razão de crises de abstinência, ou, em razão de internaçóes para tratamento da dependência química.

Nestes casos, o direito ao trabalho é violado, mas, em tese, legitimamente, pois o trabalhador terá os dias de falta descontados, ou, será dispensado por justa causa caso a ausência no trabalho ocorra por mais de trinta dias, conforme autorizada o artigo $482^{41}$, alínea 'i', da CLT.

Ainda pior do que esta violação ocorre quando o trabalhador dependente químico é dispensado por justa causa, valendo-se o empregador, por analogia do disposto na alínea ' $\mathrm{f}$ '42 do citado artigo da CLT, como ocorreu neste caso:

EMENTA: 1.Conforme estabelece o art. 482, "b”, da CLT constitui justa causa para rescisão do contrato de trabalho pelo empregador a constatação de mau procedimento do empregado. 2. "In casu", a decisão regional considerou não haver prova robusta a embasar a demissão motivada, pois, embora a evidência dos fatos trazidos pela análise das imagens por perito do juízo, não teria havido comprovação efetiva de prática de ato

40 HONNETH, Axel. Luta por reconhecimento: a gramática moral dos conflitos sociais, p. 45.

41 Art. 482 - Constituem justa causa para rescisáo do contrato de trabalho pelo empregador:

[...]

i) abandono de emprego.

42 Art. 482 - Constituem justa causa para rescisão do contrato de trabalho pelo empregador:

[...]

f) embriaguez habitual ou em serviço; 
ilícito no ambiente de trabalho a justificar sua demissão por justa causa. 3. Ora, dos elementos fáticos e do conjunto probatório delineados no acórdáo regional se percebe nitidamente o enquadramento da conduta obreira na alínea " $b$ " do art. 482 da CLT, uma vez que se evidenciou consumo de substância entorpecente em intervalo para refeiçáo e descanso no estabelecimento da Reclamada. Recurso da Reclamada provido. (TST. RR 93500-64.2009.5.03.0142. 7a Turma. Relator: Ministro Ives Gandra Martins Filho. Publicado no DEJT em 25/05/2012) (grifo nosso)

Ou seja, aqui a violação ao direito humano ao trabalho estaria, em tese, legitimada, mas somente em tese, pois é preciso uma (re)interpretação de todas as normas trabalhistas com base nos direitos fundamentais e nos direitos humanos do trabalhador, o que evitaria esta conduta.

Finalmente, outro contexto em que o trabalhador químico-dependente vê seu direito ao trabalho violado se perfaz quando, ao término do tratamento contra a dependência química, o trabalhador, recuperado, se vê diante de outro desafio: o retorno ao meio sócio-familiar e ao mundo do trabalho, o que é, inclusive, decisivo para o seu não retorno ao uso de drogas.

Ocorre que, na maioria dos casos, o trabalhador "recuperado" já possui a pecha de 'dependente químico', no sentido transgressor da palavra; bem como possui um histórico previdenciário de afastamento por dependência química, passado entáo a figurar à margem do mundo do trabalho, não lhe sendo reconhecido, ou lhe sendo negado, o direito ao emprego.

Assim sendo, em todos os casos delineados, tanto o direito humano e universal ao trabalho não é reconhecido, quanto a necessidade de proteção da categoria de trabalhadores químico-dependentes, e por esta razão, esta categoria de trabalhadores agora luta por reconhecimento, com base na teoria do reconhecimento de Axel Honneth, como se verá a seguir.

\section{Da Luta por Reconhecimento Perante o Poder Judiciário Trabalhista}

$\mathrm{Na}$ atualidade, o cenário da luta por reconhecimento dos trabalhadores dependentes químicos é, no Brasil, essencialmente, no Judiciário, seja pelo fato da sociedade brasileira ainda não enfrentar a questão da dependência química como se deve, seja pelo fato do Poder Judiciário estar na centralidade e no monopólio dos meios de solução de conflitos.

Portanto, eclodida a luta por reconhecimento, resta ao trabalhador químico-dependente, que "sofrera os sintomas das patologias oriundas das experiências de desrespeito 43 "

43 SAAVEDRA, Giovani Agostini; SOBOTTKA, Emil Albert. Introduçáo à teoria do reconhecimento de Axel Honneth. p. 14 
recorrer ao Poder Judiciário, por não encontrar apoio em outro poder estatal, até mesmo porque a sociedade se nega a ser solidária.

Pontua-se ainda que a luta por reconhecimento, nesta esfera do poder, ocorre sempre quando o desrespeito já instaurou-se, ou seja, as demandas são sempre reparatórias, e, nunca, ou quase nunca, preventivas.

Os trabalhadores químico-dependente que tiveram seu direito humano e universal ao trabalho não reconhecido, em regra, obtêm êxito na luta por reconhecimento, perante o Poder Judiciário, no Brasil, seja em razão dos princípios norteadores do Direito do Trabalho brasileiro, seja em razão da mudança de paradigma que enfrenta a Justiça do Trabalho no Brasil.

Ou seja, tendo em vista que o Direito do Trabalho brasileiro tem por essência o respeito ao trabalhador não-objeto, e, por dever, a proteçáo do trabalho, o juiz do trabalho, ao analisar as novas demandas que batem às portas do Estado, possui maior liberdade para enfrentar novas questôes, em razão da superação do positivismo puro, ou seja, da razão cega ${ }^{44}$.

Assim sendo, com base nos princípios do Direito do Trabalho o juiz do trabalho inserido no contexto de direitos humanos universais, e, com foco no paradigma da dignidade da pessoa humana, efetiva a luta por reconhecimento, ao reconhecer à categoria demandante o que lhe foi pleiteado.

Exemplos disso estão nas decisôes proferidas pelo Tribunal Regional Goiano, no ano de 2013:

EMENTA: NULIDADE DA RESCISÁO CONTRATUAL. EMPREGADO DEPENDENTE QUÍMICO. Não obstante a possibilidade de a empregadora rescindir o contrato de trabalho sem motivação, no caso em apreço restou claramente demonstrado que a despedida fora abusiva. Restaram desconsiderados, acima de tudo, a função social da empresa e o princípio da razoabilidade, autorizando, pois, a declaração de nulidade. Recurso improvido. (TRT18, RO-0002087-17.2011.5.18.0001, Rel. Geraldo Rodrigues Do Nascimento, $3^{\text {a }}$ Turma, Publicado no DeJT 27/06/2013)

Ou seja, a luta dos trabalhadores químico-dependentes, em busca do reconhecimento do direito humano ao trabalho, já alcança resultados positivos, pois, a punição disciplinar, antes incontestável, perde lugar para o tratamento médico, como deve ser.

Assim com o reconhecimento do direito humano ao trabalho desta categoria de trabalhadores, no Judiciário, além de proteger o sujeito de direito, permite que este se realize

44 WOLKMER, Antônio Carlos. Pluralismo jurídico: novo paradigma de legitimaçấo, p. 34-44. 
autonomamente, bem como cria o sentimento de solidariedade, seja na mesma categoria (a categoria dos químicos-dependente), seja em toda a sociedade, conforme pretende a teoria do reconhecimento de Axel Honneth.

Além disso, o êxito da luta pelo reconhecimento do direito humano ao trabalho, na categoria dos químicos-dependente, comprova que o trabalho é sim meio de emancipação e de (re) inserção social, embora o caminho para o reconhecimento pleno seja longo!

\section{8. (Re) Inserção Social dos Trabalhadores Toxicodependentes sob o Prisma da Teoria do Reconhecimento}

Diante do tudo que fora exposto, indubitavelmente, o "trabalho vivo" ${ }^{5}$ é meio de emancipação do indivíduo e direito humano universal, servindo a teoria do reconhecimento de Axel Honneth de base de sustentação para a luta por (re)inserção social dos trabalhadores dependentes químicos, por meio do direito ao trabalho.

Contudo, como mesmo pontua Honneth ${ }^{46}$ nunca estiveram tão escassos como hoje os esforços para garantir um conceito emancipatório e humano de trabalho.

Além disso, a sociedade brasileira ainda não engajou-se na luta por reconhecimento da categoria dos dependentes químicos, tampouco sensibilizou-se para esta questão na esfera do trabalho.

No entanto, há esperança! Conforme pontua Castell ${ }^{47}$, "o trabalho continua sendo uma referência não só economicamente, mas também psicologicamente, culturalmente e simbolicamente dominante, como provam as reaçóes dos que não o têm”.

Destaca-se que, ao tratar na teoria do reconhecimento na esfera do trabalho, Honneth $^{48}$, faz uma distinção entre a "crítica externa ao trabalho e a crítica imanente ${ }^{49}$ ".

A crítica é externa relaciona-se ao objeto criticado, na medida em que apresentam estruturas que não podem ser aplicadas generalizadamente a todos os tipos de trabalhos necessários á economia. Portanto, para haver reconhecimento na esfera do trabalho é preciso que o fato social, para o qual se busca reconhecimento, seja amplo e generalizado.

Já a crítica imanente relaciona-se à troca social, compreendendo-se o trabalho próprio como contribuição para a divisão social do trabalho, e a esfera capitalista de trabalho como incumbida de cumprir uma função de integradora da sociedade, e não apenas de

45 MACIEL, Fabrício. TORRES, Roberto. Trabalho, reconhecimento e democracia: aplicando teorias de vanguarda ao contexto periférico, p.193.

46 HONNETH, Axel. Trabalho e Reconhecimento: Tentativa de uma redefiniçáo.

47 CASTEL. Robert. Metamorfoses da questáo social, p.15.

48 HONNETH, Axel. Trabalho e Reconhecimento: Tentativa de uma redefiniçáo, p. 23 - 40.

49 HONNETH, Axel. Trabalho e Reconhecimento: Tentativa de uma redefiniçâo, p. $23-40$. 
incrementadora da eficiência econômica, devendo a ideia de trabalho decente, dotado de sentido, estar inserida nas estruturas de produção social.

Ou seja, Honneth ${ }^{50}$ critica Marx em razão do posicionamento marxista reducionista da dimensão da autorrealização no trabalho, bem como porque ele nunca entendeu a luta de classes, centro de sua teoria, como uma forma moralmente motivada.

Assim para Honneth ${ }^{51}$, o modo unilateral como Marx tratou o conflito, adotando um modelo utilitarista de conflito social, seria o seu problema, pois, ao não considerar formas positivas de trabalho como causas da luta por reconhecimento e como promovedoras do desenvolvimento humano, a luta de classes não pode ser mais tomada como uma luta por reconhecimento, senão que apenas por autoafirmação econômica, o que não o é na teoria do reconhecimento de Axel Honneth.

Aliás, Hegel ${ }^{52}$, fonte da teoria de Marx e Honneth, já assim havia afirmado ao dizer que o trabalho é uma forma de se obter reconhecimento:

$\$ 183$ - Na sua realização assim determinada pela universalidade, o fim egoísta é a base de um sistema de dependências recíprocas no qual a subsistência, o bem-estar e a existência jurídica do indivíduo estão ligados à subsistência, ao bem-estar e à existência de todos, em todos assentam e só são reais e estão assegurados nessa ligação. Pode começar por chamar-se a tal sistema o Estado extrínseco, o Estado da carência e do intelecto.

Destarte, o mundo do trabalho não deve ser compreendido como um espaço neutro, de interesses autorregulados, mas sim como uma dimensão da vida social em que elementos morais são presentes, e, portanto, por meio da luta por reconhecimento a (re)inserção social pelo trabalho é possível.

Resta claro que "o trabalho é forma legítima de integração social" 53 e, justificado o aspecto moral que o ancora, resta incontestável seu papel de fundador da dignidade do sujeito e de formador de sua identidade.

Como já observado, "a formação da autoestima se dá com a percepção de que a contribuição de alguém é significativa na reprodução da sociedade" ${ }^{54}$. E assim é no mundo do trabalho.

50 HONNETH, Axel. Trabalho e Reconhecimento: Tentativa de uma redefinição, p. 23 - 40.

51 HONNETH, Axel. Trabalho e Reconhecimento: Tentativa de uma redefiniçáo, p. 23 - 40.

HONNETH, Axel. Trabalho e Reconhecimento: Tentativa de uma redefiniçáo, p. 40-43.

52 HEGEL, George Wilhelm Friedrich. Princípios da Filosofia do Direito, p. 168.

53 MACIEL, Fabrício. TORRES, Roberto. Trabalho, reconhecimento e democracia: aplicando teorias de vanguarda ao contexto periférico, p. 186.

54 MACIEL, Fabrício. TORRES, Roberto. Trabalho, reconhecimento e democracia: aplicando teorias de vanguarda ao contexto periférico, p. 186. 
Desta forma, compreendendo-se o reconhecimento como as medidas pelas quais se efetiva a dignidade do indivíduo, é também no âmbito do trabalho que o sujeito desenvolve a sua autoestima, ambiente este formador de sua identidade e dignidade.

Portanto, reconhecer o direito humano ao trabalho ao trabalhador químico-dependente, tratando esta nova demanda social no viés da proteção e da recuperação do trabalhador, é reconhecer a própria dignidade e propiciar-lhes a (re)inserçáo social por meio do trabalho.

Neste contexto, a empresa também ocupa importante papel na (re)inserção social do trabalhador toxicodependente, não só em termos de acesso ao emprego, mas, também mediante a oferta de meios de manutenção do emprego aliados a tratamento da enfermidade da dependência química.

A Empresa Brasileira da Aeronáutica - Embraer - é pioneira na criação de programas de combate à dependência química dos trabalhadores. Criado em 1999, o denominado 'Programa de Controle e Recuperação do Dependente Químico', o projeto da EMBRAER promove campanhas internas, promovidas por médicos do trabalho e psicólogas, que incentivam a busca por tratamento de conscientização dos riscos da dependência química no ambiente de trabalho ${ }^{55}$.

A relevância deste investimento pela empresa reflete na produtividade. Dados American Management Association- da AMA mostram que 65\% dos acidentes de trabalho nos Estados Unidos estão ligados ao uso de álcool e de outras drogas e que o custo anual, somando perdas patrimoniais, acidentes de trabalho, baixa produtividade e despesas médicas, entre outros fatores que envolvem usuários de drogas, foi de US\$ 180 bilhóes nos Estados Unidos em 2013. No Brasil, projeçôes da associação americana chegam a cerca de US\$ 19 bilhóes $^{56}$.

Por outro lado, os programas de combate e prevenção do uso de drogas não demandam altos investimentos. Dados do Banco Interamericano de Desenvolvimento- BIDmostram que, para cada dólar investido pelas empresas em tratamentos a dependentes químicos, existe um ganho de US\$3, a redução de $91 \%$ das faltas, diminuição de $88 \%$ dos problemas disciplinares e $97 \%$ menos casos de acidentes de trabalho. ${ }^{57}$

Portanto, não basta mais que a empresa simplesmente cumpra as obrigaçóes contratuais e legais. É preciso que os detentores dos meios de produção se conscientizem de seu papel na sociedade, atuando em prol da sociedade, reconhecendo e efetivando direitos.

55 Mais informações em http://www.ismabrasil.com.br/trabalho/19

56 Dados disponíveis em http://www2.uol.com.br/aprendiz/guiadeempregos/executivos/info/artigos_200 904.htm\#1

57 Dados extraídos do Programa de prevenção de uso de drogas desenvolvido pelo Banco Interamericano de desenvolvimento, disponível em: http://www.iadb.org/es/proyectos/project-information-page,1303. html?id=TC9811047. 
Tais procedimentos fundamentam-se na função social da empresa, esculpido na Constituiçãao Federal e, neste caso, interpretado no sentido de que a empresa deve proporcionar ao seu empregado um tratamento digno para que o mesmo possa ser reconhecido e (re)inserido socialmente.

\section{Conclusões}

Para se chegar a estas conclusóes que seguem, buscou-se, primeiramente, analisar os Direitos Humanos sob o prisma de sua pretensão de validade universal, bem como analisar as nuances básicas da teoria do reconhecimento de Axel Honneth, sob pena de divagação inútil acerca da necessidade de análise do problema proposto, qual seja: a necessidade de reconhecimento dos trabalhadores dependentes químicos.

Em um segundo momento, após a (re)construção do trabalho, para além do paradigma capitalista, pontuando que o trabalho é sim meio de dignificação do homem e, após a definição de contorno básico do que foi o objeto de estudo denominado: 'trabalhador dependente químico', pontuou-se que a teoria do reconhecimento é a ferramenta de enfrentamento ao ataque ao direito humano e universal ao trabalho, no contexto em que o trabalhador dependente químico vê-se não reconhecido como sujeito de direitos que é, carente de proteção e não de exclusão.

Isto para que ao final fosse possível fundamentar que (re)inserção social do trabalhador químico-dependente, por meio do reconhecimento do direito humano e universal ao trabalho, é possível.

Portanto, em conclusão, afirmamos que pelo trabalho postula-se reconhecimento. É sim possível a reinserção social por meio do trabalho, haja vista que o trabalho é parte do homem. Porém, as condições em que o trabalho se desenvolve nem sempre são as ideais, não alienadas ou não objetadas.

Claro está neste texto que o não reconhecimento de um direito humano universal, o direito ao trabalho, é patente no que tange aos trabalhadores químico-dependentes, isto porque o adoecimento que os acomete os impede de participar da construçáo da sociedade.

No Brasil, esse cenário é gritante. Especialmente na categoria dos trabalhadores químico-dependentes, cada vez mais o não reconhecimento do direito ao trabalho é deflagrado, o que impede a participação destes trabalhadores no processo social, gerando uma categoria de trabalhadores socialmente excluídos.

Entretanto, se o mundo do trabalho for compreendido a partir de uma noção de justiça social, cujos direitos inerentes ao homem trabalhador, ao trabalho vivo, serão efetivados por atitudes de reconhecimento em sua concepção mais ampla, sem a necessidade 
talvez da atuação reparadora do Poder Judiciário, pois o dano não mais ocorrerá, a (re) inserção social do dependente químico por meio do trabalho será possível.

Contudo, sem a consciência de que o outro é um semelhante, não há condiçóes de dotá-lo com valores morais que direcionem o nosso agir. Logo, primeiramente, deve-se consumar o reconhecimento elementar, espontâneo, pois, somente assim o reconhecimento, pela estima, será possível.

Na medida em que reconhecer é afirmar a dignidade ínsita ao seu estatuto de pessoa, à sua identidade, reconhecer alguém irá impor condutas tanto para aquele que é reconhecido quanto para aquele que reconhece.

É preciso também salientar que a partir da necessidade do reconhecimento do outro será possível a formação de um conceito ampliado de justiça que reaproxime moral e direito, o que já pode ser vislumbrado, dentre outros exemplos, na promoção de açóes afirmativas como cotas para pessoas com deficiência e na forma como vem sendo tratada ultimamente a questão da saúde do trabalhador.

Neste contexto, deve haver uma reflexão sobre o novo papel que deve assumir o Direito do Trabalho como instituição. A questão é modernizar, adaptando o Direito do Trabalho ao cenário presente para que seja hábil a propor soluçôes às indagaçôes que se apresentarem. Numa sociedade "pós-moderna”, há a necessidade de soluçôes “pós-modernas".

Assim, o trabalhador, mesmo que químico-dependente ou recuperado desta enfermidade, ao ter seu direito ao trabalho reconhecido poderá (re)inserir-se na sociedade, pois dotado de dignidade, e assim será tratado.

Isto porque o reconhecimento formal de uma capacidade igual, no que diz respeito aos direitos, muitas vezes, não é suficiente. Assim, as questôes articuladas dentro de um conceito ampliado de justiça são propícias a alcançar maior amplitude do campo da eficácia. É preciso que o Direito do Trabalho reconheça o trabalhador.

Além disso, a realização da função social da empresa, por meio do reconhecimento do trabalhador toxicodependente e a promoção e valorização deste indivíduo, mediante o acesso ao emprego decente, importará na redução das desigualdades e sociais e na efetivação da dignidade da pessoa humana.

Assim, a partir daí, o trabalho poderá ser o meio pelo qual a luta por reconhecimento importará na (re)inserção do trabalhador toxicodependente na sociedade.

\section{Referências}

ANDRADE, Everaldo Gaspar Lopes de. Princípios de Direito do Trabalho e seus Fundamentos Teórico-Filosóficos: Problematizando, refutando e deslocando o seu objeto. 1. ed. São Paulo: LTr Editora, 2008. 
ARAÚJO NETO, José Aldo Camurça de. A categoria “reconhecimento" na teoria de Axel Honneth, p. 78.

ASSY, Bethânia; FERES JÚNIOR, João. Reconhecimento. Disponível em: http://www. filosofia.ufc.br/argumentos/pdfs/edicao_5/18.pdf. Acessado em 10/11/2013.

BARROSO, Luís Roberto (org.). A Nova Interpretação Constitucional: Ponderaçáo, Direitos Fundamentais e Relaçóes Privadas. 2 ed. Rio de Janeiro: Renovar, 2006.

BENJAMIN, Walter. A Modernidade e os Modernos, Rio de Janeiro: Tempo Brasileiro, 1975.

BERMAN, M. Tudo que é sólido se desmancha no ar: a aventura da modernidade. São Paulo: Companhia das Letras, 1986.

BRASIL. Constituição (1988). Constituição da República Federativa do Brasil. 32a . ed. São Paulo: Saraiva, 2010.

BRASIL. Decreto Lei no 5.452 de $1^{\circ}$ de maio de 1942. Consolidação das Leis do Trabalho. $15^{\text {a }}$ ed. São Paulo: Saraiva, 2011.

BRASIL. Ministério Saúde. Código Internacional de Doenças. Disponível em: http:// www.datasus.gov.br/cid10/V2008/cid10.f79htm. Acessado em 20/11/2013.

BRASIL. Presidência da República. Relatório brasileiro sobre drogas. Brasília: SENAD, 2009.

BRASÍLIA. Tribunal Superior do Trabalho. Demissão por justa causa. Art. 482, - b da CLT - Mau Comportamento - Caracterização. RR 93500-64.2009.5.03.0142. $7^{\mathrm{a}}$ Turma. Relator: Ministro Ives Gandra Martins Filho. Diário Eletrônico da Justiça do Trabalho. 25/05/2012.

CARDOSO, João Santos. A discussão filosófica da modernidade e da pós-modernidade. Revista Metavola, v. 13, p. 34/13-46, 2011.

CASTEL. Robert. Metamorfoses da questáo social. Petrópolis: Editora Vozes, 1998.

COMPARATO, Fábio Konder. A afirmaçáo histórica dos direitos humanos. $2^{\mathrm{a}}$ ed., São Paulo, Saraiva, 2001.

DEJOURS, Jacques Christophe. A loucura do trabalho: estudo de psicopatologia do trabalho.

. A banalizaçáo da injustiça social. Trad. Luiz Alberto Monjardim. Rio de Janeiro: Fundação Getúlio Vargas, 2001.

A loucura do trabalho: estudo de psicopatologia do trabalho. São Paulo: Cortez-Oboré, 1992. 
DIAS, Maria da Graça dos Santos; MELO, Osvaldo Ferreira de; SILVA, Moacyr Motta da. Política jurídica e pós modernidade, 2001. Disponível em: http://www.redalyc.org/articulo.oa?id=74211531002. Acessado em 10/11/2013.

DURKHEIM, Émile. Da divisáo do trabalho social. São Paulo: Martins Fontes, 1999.

DUSSEL, Enrique. Hacia um Marx desconocido: un comentario de los manuscritos del 61-63. México, D.F., Siglo XXI/Iztapalapa, 1988.

FERREIRA, Aurélio Buarque de Holanda. Novo dicionário Aurélio da língua portuguesa, 2012.

GOIÂNIA. Tribunal Regional do Trabalho. Nulidade da rescisáo contratual. empregado dependente químico. RO-0002087-17.2011.5.18.0001, Rel. Geraldo Rodrigues Do Nascimento, $3^{\text {a }}$ Turma. Diário Eletrônico da Justiça do Trabalho, 27/06/2013.

GONTIJO, Lucas Alvarenga. Direitos Humanos sob o prisma da Filosofia do Direito: desafios e discursos de justificaçáo dos direitos humanos nas sociedades contemporâneas. Disponível em: http://pt.scribd.com/doc/181554677/693073-Direitos-Humanos-Sob-o-Prisma-Da-Filosofia-Do-Direito-1. Acessado em 10/09/2013.

HEGEL, Georg Wilhelm Friedrich. Princípios da Filosofia do Direito. Tradução de Orlando Vitorino. São Paulo: Martins Fontes, 1997.

HONNETH, Axel. Luta por reconhecimento: a gramática moral dos conflitos sociais. 2. ed. São Paulo: Ed. 34, 2009.

. Trabalho e Reconhecimento: Tentativa de uma redefinição. Civitas - Revista de Ciências Sociais. Porto Alegre, v.8, n.1, p. 46-67, jan/abr.2008.

LARANJEIRA, Ronaldo; PINSKY, ILana; ZALESKI, Marcos; CAETANO, Raul. I levantamento nacional sobre os padróes de consumo de álcool na populaçáo brasileira. Disponível em: http://bvsms.saude.gov.br/bvs/publicacoes/relatorio_padroes_consumo_alcool.pdf. Acessado em 20/11/2013.

MACIEL, Fabrício. TORRES, Roberto. Trabalho, reconhecimento e democracia: aplicando teorias de vanguarda ao contexto periférico. Disponível em: http://www. lume.ufrgs.br/bitstream/handle/10183/24824/000749413.pdf? sequence $=1$.Acessad o em 10/11/2013.

MAYOS, Gonçal. O problema sujeito-objeto em Descartes, perspectiva da Modernidade, traduzido por Mariá Brochado e Natália Freitas Miranda. Originalmente publicado como "El problema sujeto-objeto en Descartes, prisma de la modernidad". Pensamiento - Revista de investigación e información filosófica, Madrid, n. 195, V. 49, pp. 371-390, jul.-sep. 1993. 
MARSHALL, Thomas. H. Cidadania, Classe Social e Status. Rio de Janeiro: Zahar Editores, 1967.

NOGUEIRA, Eliana dos Santos Alves. O Novo Direito do Trabalho na Pós-Modernidade e o papel da Justiça do Trabalho. Revista do Tribunal Regional do Trabalho da 15a Região. Campinas, n. 22, p. 209-219, jun. 2003.

ORGANIZAÇÃO MUNDIAL DA SAÚDE. Informaçóes sobre drogas. Disponível em: http:/www.obid.senad.gov.br/portais/OBID/conteudo/index.php?id_conteu$\mathrm{do}=11250 \&$ rastro=INFORMA $\%$ C3\%87\%C3\%95ES+SOBRE+DROGAS/Defini\%C3\%A7\%C3\%A3o+e+hist\%C3\%B3rico. Acessado em 20/11/2013.

ORGANIZAÇÃO MUNDIAL DE SAÚDE. Relatório mundial de saúde. Disponível em: http://www.who.int/whr/2001/en/whr01_po.pdf. A cessado em 20/11/2013.

ORGANIZAÇÃO INTERNACIONAL DO TRABALHO. Problemas ligados a álcool e drogas no local de trabalho: Uma evolução para prevenção. Primeira Edição. Setembro 2008. Palmira Artes Gráficas, 2008.

OLIVEIRA, Sebastião Geraldo de. Proteção Jurídica à Saúde do Trabalhador. São Paulo: LTr, 1996.

OLIVEIRA, Olivan Liger de. Álcool e drogas no ambiente corporativo: a importância dos programas de prevençáo e reabilitaçáo do trabalhador dependente químico. Disponível em: http://www.nucleodepesquisas.com.br/artigos/alcool-edrogas-no-ambiente-corporativo-a-importancia-dos-programas-de-prevencao-e-reabilitacao-do-trabalhador-dependente-quimico. Acessado em 20/10/2013.

PIMENTA, José Roberto Freire. A tutela metaindividual dos direitos trabalhistas: uma exigência constitucional. In Tutela Metaindividual Trabalhista: A defesa coletiva dos direitos dos trabalhadores em juízo. PIMENTA, José Roberto Freire; BARROS, Juliana Augusta Medeiros de; FERNANDES, Nadia Soraggi (coord). São Paulo: LTR, 2009.

RAVAGNANI, Hebert Barucci. Luta por reconhecimento: a filosofia social do jovem Hegel segundo Honneth. Kínesis, vol. I, n. 01, Março, 2009, p. 39-52.

RICOEUR, Paul. Percurso do reconhecimento. Tradução de Nicolás Nyimi Campanário. São Paulo: Loyola, 2006.

SAMPAIO, José Adércio Leite. Direitos Fundamentais: retórica e historicidade. Belo Horizonte: Del Rey, 2004.

SILVA, Guilherme Ferreira. Os direitos humanos sob a ótica materialista e procedimentalista. In: Âmbito Jurídico, Rio Grande, XV, n. 105, out 2012. Disponível em: <http://www.ambito-juridico.com.br/site/index.php/?n_link=revista_artigos_leitura\&artigo_id=12290\&revista_caderno=15>. Acesso em set 2014. 
SILVA, José Antônio Ribeiro de Oliveira. A Saúde do Trabalhador como um Direito Humano: conteúdo essencial da dignidade humana. 1 ed. São Paulo: LTr, 2008.

SILVA, Josué Pereira da. Trabalho, Cidadania e Reconhecimento.1. ed. São Paulo: Annablume, 2008.

SOBOTTKA, Emil A.. Liberdade, reconhecimento e emancipação - raízes da teoria da justiça de Axel. Disponível em: http://www.scielo.br/scielo.php?pi$\mathrm{d}=$ S1517-45222013000200006\&script=sci_arttext. Acessado em 10/11/2013.

TAYLOR, Charles. The politics of recognition. Disponível em: http://elplandehiram.org/documentos/JoustingNYC/Politics_of_Recognition.pdf. Acessado em $10 / 11 / 2013$.

WOLKMER, Antônio Carlos. Pluralismo jurídico: novo paradigma de legitimaçáo. Mundo Jurídico, [s.1.], 2003. Disponível em: <http://www.mundojuridico.adv.br>. Acesso em 10/09/2013. 